\title{
Preemptive and Reactive Focus-on-Form Instruction: Effect on learning parallel grammatical structures
}

\begin{abstract}
:
The present study set out to investigate the differential effect of focus-on-form (FonF) instruction. Two research questions were raised: 1) Does FonF instruction,both preemptive and reactive, have a differential effect on learners' interlanguage? 2) Are shortterm gains, if at all, maintained in the long-term? Fifty one (51) third-year LMD university English language learners are divided into two groups: a FonF group $(\mathrm{N}=27)$, and a Control group $(\mathrm{N}=24)$. Parallel structures were selected as the target form. A Grammaticality Judgment Test (GJT) was used to measure accuracy of the target form over the short- and the long-term; therefore, three similar but not identical tests were administered at three temporal times: a pre-test, an immediate post-test, and a delayed post-test. The results of the present study showed that FonF instruction had a differential effect in language learning in both the short- and the long-term. Recommendations for both research and pedagogy are discussed.
\end{abstract}

Key words: Instruction - focus on form - input enhancement feedback - consciousness-raising.

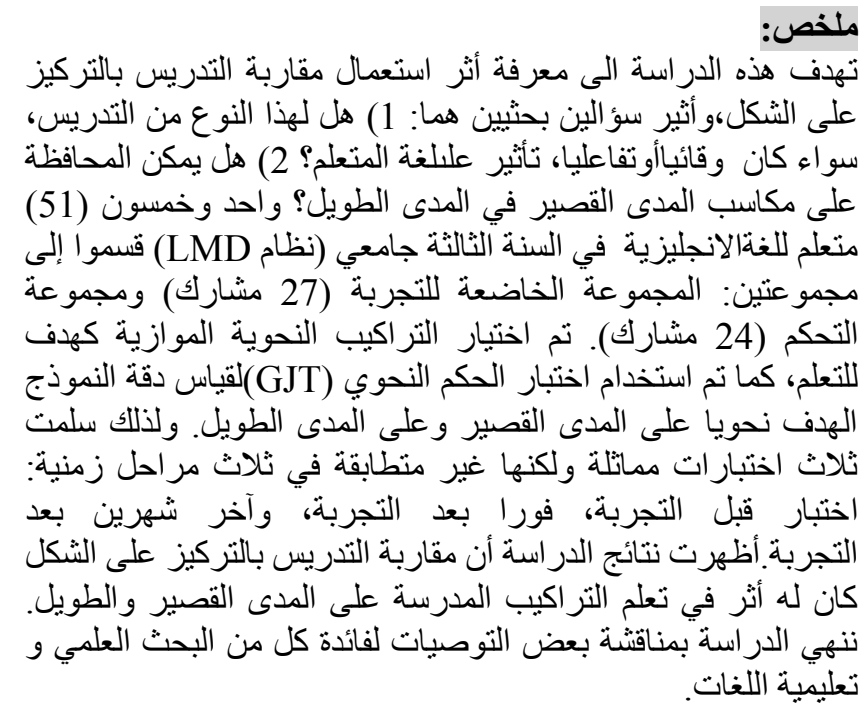

\section{Fouad BOULKROUN}

Faculty of Letters and Languages

Department of Foreign Languages

University of Mentouri

Constantine

\begin{abstract}
Introduction:
Let it be stressed that the ultimate aim of language teaching/learning is to produce functionally competent performers who are not at a disadvantage, or short, of grammatical equipments. Yet, undue focus on meaning (FonM) or communicative skills at the cost of forms (FonFs) or grammatical accuracy results in learners who stop developing at a grammatically inaccurate level of proficiency.
\end{abstract}


Evidence from several immersion studies suggests that, in a purely communicative context, some L2 forms do not develop to target-like accuracy in spite of years of meaningful, comprehensible input and interaction [1]. This justifies, then, the motivation for formal instruction, i.e. the inclusion of grammar, an issue that constitutes the cornerstone of the endless debate in L2 teaching methodologies: should we teach grammar at all?

It is our contention that focus-on-form (FonF) instruction should be adopted as a mediator between FonFs and FonMby teaching grammar in situations where the focus is primarily on meaning and communication [2; 3], an alternative which has, certainly, consequences for language learning and instruction.Focus on formcan be practised either pre-emptively such that exposure to and use of linguistic forms are determined in advance, or reactively in the form of feedback.

\section{Grammar On/Off the Defensive}

The debate over grammar seems a war that never ends. Whether or not grammar should be taught is a question that has been continually debated in second language acquisition (henceforth, SLA). Researchers like Krashen[4] argued that grammar is acquired naturally and second language (L2) learners need only be exposed to rich comprehensible input; as such, to the question of whether grammar should be taught the answer is in the negative because with the provision of comprehensible input it is believed that grammar will look after itself.

Other researchers held quite the opposite view, a view in favour of the inclusion of formal grammar instruction. According to White [5], given that mere exposure to L2 input does not guarantee the acquisition of all grammatical forms, it follows that grammar should be taught. Likewise, Larsen-Freeman [6] argued that granting that grammar is acquired naturally, it does not mean that grammar instruction is not necessary. This is so because teaching grammar can enhance its acquisition and speed up the learning process.

\section{Instruction}

For the purposes of the present study, it is worth our while to define what formal instruction is. Cadierno [7] defines it as follows: "any attempt by teachers to intervene directly in the process of interlanguage construction by providing samples of specific features for learning" (p.179). As a matter of fact, the importance of teacher intervention, or say instruction, cannot by any means be denied. Instruction is likely to secure provision of, mainly, input that is not, say, enhanced, and an environment for focus-on-form instruction [8].

Now, is grammar instruction all that necessary? In point of fact, as Baars pointed out, and N. Ellis [9] quoted: "The more novelty we encounter, the more conscious involvement is needed for successful learning and problemsolving" (p. 306).Inaddition, N. Ellis argued that implicit processes alone do 
not guarantee full acquisition for the mere reason that various aspects of a L2 are unlearnable. In case of a communication breakdown, for example, we tend to negotiate meaning and we come to learn a lot about form. In this way, grammar is necessary for meaning construction.

Over the years, there has been a growing concern among researchers, theorists and teachers alike about the effect, if at all, of formal instruction on SLA. Put another way, does formal instruction make a difference in L2 acquisition?

\subsection{Effect of Instruction}

Formal instruction is at the very heart of the debate in SLA and has been subject to controversy among researchers for years [10; 11]. Looking back at the debate over the past 30 years or so, L2 instruction research seems to have raised two major questions - among others. These are the issue of whether formal instruction has any effect on SLAand whether it is beneficial, an issue seemingly controversial [12].

As indicated by Long [10], the question of whether instruction makes any difference at all can be answered by a number of comparisons. Reviewing research findings and making comparisons between twelve studies exploring the effects of instruction, Long held that there is ample evidence showing that instruction does make a difference (though he pointed out that this runs contrary to the claims advanced by Krashen's Monitor Theory). Long also added that such findings, being based on the studies he reported, are worthy to be discussed for they have implications and yield supporting or disconfirmatory evidence for theories - such as Krashen's Monitor Theory - which make predictions about SLA with the provision or withholding of L2 instruction. They are worthy to be discussed also because, as he put it, these findings speak tothe efficacy or utility of instruction (and/or exposure).

\subsection{Reviewing the Experimental Research on Effects of Instruction}

In what follows, I attempt to review briefly two experimental studies on the effect of instruction on learners' interlanguage. The selected studies compared instructed learners who received experimental treatment to other learners with no focused instruction.

Harley [13] demonstrated that formal instruction contributes to SLA. His study investigated the acquisition of French tense-aspect, namely the distinction between 'passé composé' and 'imparfait' by immersion students in Canada. The effect was lasting for the experimental group who did not lose ground, which was not the case for the control group. Harley, thus, pointed out that instruction was effective in both planned (written composition, cloze test) and unplanned language use (oral interview).

Pushing further on these lines of thought, the lines that hold evidence for the benefit of formal instruction, White [14] conducted an experiment about adverb placement with Canadian French learners of English. Again, the 
experimental group performed better on different tasks. Yet, their accuracy faded in the delayed post-test. This provides ample evidence that formal instruction, in spite of the fact that it may have short-term effects, helps foster language accuracy.

\section{Focus-on-Form Instruction}

Ever since Long [10] demonstrated that instruction makes a difference in SLA, as opposed to simple naturalistic exposure, a research agenda has emerged in L2 instruction (see below) prompting the adoption of grammar instruction while coupling it with communicative language use, the thing that would make it possible for learners to hit two birds with the one stone: hitting language use and language accuracy altogether. The major concern of such research has eventually shifted from whether instruction, in formal contexts, has the potential to affect L2 acquisition to what types of instruction are most effective. Studies on types of instruction assume that instructional treatments should aim at effecting change in learners' focal attention during L2 processing [15]. In this way, certain L2 forms are likely to be noticed [16] and therefore acquired.

According to Long [17], it is inadequate to teach grammar out of context just as it is to teach language in a purely communicative fashion. This is so simply because the former approach tends to handicap L2 learners in their use of grammar forms communicatively and because the latter gives little, if any, importance to grammar instruction. Given that this is so, Long proposed a third approach called focus on form(henceforth, FonF)which would match communicative language use with grammar instruction in context, an approach that is task-based in instruction.

FonF instruction (also termed FFI, an acronym standing for formfocused instruction) $[18 ; 12]$, which presents the linguistic form, as it arises incidentally or in a planned way (see below), in a lesson within a meaningful context, is said to securea balance between a FonFsand a FonM, thus bridging the gap between traditional formal instruction (with a FonFs) and the full communicative use of language or FonM (see the study of Ellis et al [19] which is an indication that FonF can take place with no risk of disturbing the communicative flow of a classroom).FonF instruction has at least two advantages in that it makes positive evidence more salient, and it provides essential negative evidence through direct or indirect negative feedback [20].

\subsection{Types of Focus-on-Form Instruction}

A number of L2 researchers hold that communicative instruction should draw learners' attention to linguistic forms so as to build a wellbalanced communicative competence $[21 ; 22 ; 23 ; 3]$. This approach has come into vogue notwithstanding the diversity in terminology use and practice of the approach. Doughty et al [23] argued that it is timely now to account for and 
clarify terminology and research issues relating to FonF studies, mainly because of the disagreement and diversity in handling such a construct.

\subsubsection{Preemptive vs. ReactiveFonF Instruction}

Long et al [3] distinguished between preemptive FonF and reactive FonF. In a preemptiveapproach to $\mathbf{F o n F}$, exposure to and use of linguistic forms are determined in advance: the teacher or the learner attempts to attend to a linguistic form, with the use of structured or enhanced input for example, because it might prove problematic later. The latter type comes into play when a learner uses a linguistic form that appears to be erroneous and a participant reacts to the error by requesting clarification (a kind of feedback), for example.

\subsubsection{Planned vs. Incidental FonFInstruction}

Pushing further on the terminology pertinent to different types of formal instruction, and without losing sight of Long's [2] definition, Ellis [11] distinguished between planned FonF and incidental FonF. He defined FonF as "any planned or incidental instructional activity that is intended to induce language learners to pay attention to linguistic form" (pp. 1-2). In the former type, FonF takes the form of prior planning on the part of the researcher or teacher $[24 ; 25]$, prompting the learner to attend intensively to preselected forms [11]. In the latter, learners attend, extensively, to a number of forms but none is preselected for subsequent instructional treatment $[26 ; 11 ; 27 ; 28]$.

\subsubsection{Implicit vs. Explicit FonF Instruction}

Researchers such as DeKeyser [29], Harley [30], Lightbown [31] defined FonFin broader terms; there is, according to them, room for, among other things, explicit positive/negative evidence and metalanguage. Spada [18] accounted for the construct in both implicit (e.g., use of recasts) and explicit terms (e.g., metalinguistic feedback, explicit correction, etc.).

Central to the discussion on FonF, then, is the notion of feedback. An important issue addressed by research studies, along the FonF perspective, is the positive role of correctivenegative feedback and its impact on interlanguage development. In this perspective, FonF is seen as being reactive in approach (i.e., teacher provision of feedback in reaction to students' utterances that contain a linguistic error) and can take place either implicitly (e.g., the use of recasts) or explicitly (e.g., the use of explicit correction).

It is worthy to mention that such differences add welcome new data to the bulk of information at hand but as it is customary we share the view that operational definitions of these distinct types of FonF, and so labels, are urgently in order.

\subsection{Reviewing Experimental Research on the Effect of FonF Instruction}

FonF research has, as yet, put theories of instructed SLA to the test by tracking the linguistic progress of different learners exposed to different instructional types or techniques. This explains very well why specific 
pedagogical techniques have been investigated and compared in these last decades. Let us now review the bulk of the research into the effects of different types of L2 instruction to date.

Lightbown et al [22] observed the development of spoken English of French elementary school students in Quebec receiving five months of intensive English as a second language (ESL) communicative instruction. They concluded that FonF, might well yield to accurate linguistic proficiency and performance. Similar results were found in a Canadian study conducted by Spada et al [32] on the effects of FFI and corrective feedback on the development of several English structures by young (10-12-years-old) learners in an intensive ESL course.

Another study on the very effects of type of instruction on L2 acquisition is Doughty's [33]. She concluded that formal instruction, orFonF, in which saliency and frequency of the target form were enhanced, was optimal for L2 acquisition. The pedagogical implication may be that teachers can direct learners' attention to language forms effectively within meaning-oriented instruction if saliency and abundancy of forms are made use of.

Harley [30] conducted a study on FonF instruction and its effect on young L2 French immersion learners having as a target French gender. The experiment yielded results very much in keeping with the aforementioned, that participants focusing on form outperformed those having no focus and even had a metalinguistic knowledge of French gender.

In the same perspective, Sharwood Smith [15] held that language learners' consciousness can be raised by using enhanced input which is possible by way of typographical modifications of target forms in a written passage. Leeman et al [34] investigated the effects of FonF on the use of the Spanish past and imperfect in a communicative classroom. No wonder, again, type of instruction, namely FonF, did make a difference.

Doughty et al [35] examined the effect of FonF, in a communicative context, on the acquisition of the simple past and the conditional past by 34 ESL content-based science class learners in a middle school. The science reports which the students wrote and presented in class included both target forms. Instruction targeted planned and unplanned use of the simple past and the conditional past. In the oral reports, the subjects in the FonF group (21 in number) achieved a significant increase in the use of the forms under study. As for the control group (13 subjects in number), no improvement took place.

Day et al [36] investigated the instructional effectiveness of FonF in Canadian French immersion programmes. They conducted an experiment on the use of the conditional. The study yielded findings indicating that the participants of the experimental group bettered their performance, and their gains were maintained in the post-tests. Again, this is consonant with the 
hypothesis that formal instruction affects positively L2 acquisition in general and learners' production accuracy in particular.

To summarize, it has been demonstrated, so far, that research on instructed SLA provides diverse examples of the positive influence that FonFinstruction has on the development of learners' interlanguage.

\subsection{Factors Interacting with FonF}

Yet, as the saying goes, language learners are not all of a kind; the preceding discussion, however, might have given, so far, the reverse impression - the impression that they are. In spite of evidence to the contrary, several studies dealt with learners as one body in that they paid little attention to individual differences (see the studies reported by Williams [1]). The following are some of the most important variables believed to be at work in FonF instruction: developmental readiness (or say internal status of a learner's interlanguage) and natural orders of acquisition, the nature and complexity of target structures, individual differences like age, the affective filter, the Monitor, aptitude, attitude, learning styles - to name but a few. Yet, Rod Ellis [12] maintained that it is difficult to bring the discussion on the variables that have an impact on success to a consensus; in spite of this, his analysis of the eleven studies, he assured, was suggestive of what these factors might be.

\section{Method}

For reminder purposes, to determine the role of FonF instruction in the acquisition of English parallel structures, this paper has addressed two research questions:

1. Does instruction through $\mathbf{F o n F}$, both preemptive and reactive, make a difference in the short-term learning of target structures?

2. Does FonFinstruction maintain its effects in the long run?

Having advanced the research questions, let us specify the comparisons to be conducted by translating the afore-stated research questions into workable hypotheses.

\section{Hypothesis 1}

I hypothesize that instruction makes a difference in that the FonF instructed group would have differential effects on the short-term-learning of parallel structures, i.e. the FonF subjects who receive a focused treatment would outperform the uninstructed participants of the control group - those who receive no focused instructional treatment. Thenull hypothesis would be that instruction does not make a difference or that there is no difference in the short term learning of parallel grammar structures between the two groups.

\section{Hypothesis 2}

I hypothesize that short-term gains will be maintainedin the long-term for the FonF group. The null hypothesis would be that the gains of instruction will not be maintained in the long-term.

\subsection{Sample:}


The subject sample of this study consisted of 51 third year LMD university English language learners from the University Centre of Mila, selected randomly from the parent population; intact classes, that is, were assigned to different groups. Of note, only the participants from the 2 classes who were present in all temporal phases of the experiment were accounted for.

Two groups have been compared: one experimental group and one control group. An intact class was randomly selected by the researcher as the experimental group. Subjects in this condition received focused input, targeting parallel grammatical structures.

To test whether or not instruction makes a difference, an intact class was randomly selected by the researcher as the control group. It followed its normal instruction according to its prescribed syllabus. It did not receive any particular focused instructional treatment. It was used so as to find out whether L2 learners make their way to native-like grammatical knowledge without instruction specifically focused on the targeted structures. Given that this is so, the hypothetical differential effect of focused instruction is checked against unfocused instruction.

\subsection{Instruction}

Instruction took place in the regular class hours, with 4 sessions, sixtyminutes each, over a period of time equalling 4 sequential weeks (i.e. a full month), and it was given by the researcher who happened to be their teacher.

Participants in the control group followed their regular syllabus without receiving additional input specifically focused on target forms. Subjects of the experimental group, three days after the pre-test (see below), received their experimental treatment which consisted of formal instruction on the target linguistic structures - this is respectively the FonF condition in which positive evidence was made more salient (preemptiveFonF), and essential negative evidence (reactive FonF) was provided.

Instruction followed the spirit of the three Ps (the presentation, practice, and production stages). The FonF subjects were first presented with an overview of parallelism through formal instruction. All along the instruction, they were exposed to a preemptive $\mathbf{F o n F}$ with intensive attention to preselected forms while processing input for meaning. They received a reading on three themes (choosing a career, cloud types, and diet and exercise) with comprehension questions: they were required to answer the questions such that they used the forms under focus. Target forms were enhanced typographically, through the reading text, by way of underlining and the use of bold characters to draw learners' attention to both meaning and form at the same time. For reminder purposes, (preemptive) enhancement is claimed to foster learners' noticing of targeted structures.

The training tasks (which included sentence correction, gap-filling, and sentence completion) were an attempt on the part of the researcher to focus the 
participants' attention on the use of parallelism in English. This was coupled with negotiation of meaning. Grammar instruction and meaning-based interaction merged through grammar consciousness-raising tasks. It was hoped that participants would develop knowledge of the target formal featuresfor further communicative use.

Subjects were informed, right from the outset, to pay attention to the way parallel structures were used. All along the experimental training - where positive evidence was abundant - negative evidence for incorrect realizations of parallelism was provided for the subjects in the form of (reactive) explicit corrective feedback. That is, during the focused tasks, immediate feedback was provided to help learners notice the formal features of the target language. Feedback was often used explicitly, but the implicit type was also made use of in the form of recasts and clarification requests, notably.

\subsection{The structures:}

The present study set out to investigate whether FonF instruction affects L2 learning of parallel grammatical structures. We chose parallelism because after 20 years or so of teaching written expression, it seems that the best of students suffers still from this structural problem.

\subsection{Instruments:}

A small scale but intensive pilot study was then conducted, on 12 students who were not included in the final study, in order to assess the instruments utilized - namely, the three administered tests and to find out whether the selected structures were characteristic of learners' interlanguage. Upon analysis, nothing was apparently attractive, meaning that the test was both unambiguous and within the respondents' reach.

Three similar but not identical tests made up the pre-, post-, and delayed post-test. All administered tests consisted of an untimed Grammaticality Judgment Test.

\subsubsection{The Untimed Grammaticality Judgment Test}

The development of L2 grammatical parallel structures was measured by means of an untimed paper-and-pencil Grammaticality Judgment Test (GJT), targeting explicit knowledge of the structures under study.

As a matter of fact, GJTs require the L2 learner to indicate whether a particular item is grammatically correct or incorrect. The test-takers were given a number of sentences containing correct and incorrect realizations of the target structure, and were instructed to identify which was which. Eight sentence items were correct and eight incorrect, giving a total of sixteen sentences. There was no time pressure, meaning the respondents did not complete the tests under time constraints; they worked rather in their own time.

Why the untimedGJT? A number of considerations motivated the choice for a GJT. One reason why may be the fact that the untimed GJT is designed to measure explicit knowledge. Explicit knowledge tests, by 
definition, call on one's explicit knowledge of a particular rule of grammar, prompt its use as a monitor, allow the test-taker some processing time, and focus attention on form. A second reason is that comprehension usually takes place before production and the GJT requires more passive grammar knowledge in comparison with other tests. One may conjecture a guess: why not test oral proficiency? The answer is that instruction is believed to affect written, before oral, proficiency; oral language use, being more timeconstrained, requires higher degrees of automatization (Bialystok [37; 38]).

The GJT was administered at three different temporal points all along the experiment: one before the treatment (Test/Time 0 ), a second immediately after the treatment (Test/Time 1), and a third delayed two months after the treatment (Test/Time 2). As such, the experiment stretched over a period of almost four months (including the pilot test). It may be worth our while to note that, so as to avoid the likelihood of subjects completing the post-tests while drawing on some memorized input, no test sentence bore any resemblance to the sentences included in the treatment condition.

\subsubsection{The Pre-test}

The test, delivered in written form, consisted of 16 sentences, divided evenly between grammatical and ungrammatical and running hierarchically across different levels: the word, the phrase, and the clause levels, respectively. Test-takers were required to indicate in their own processing time whether each sentence was grammatical or ungrammatical by ticking where appropriate. The pre-test was meant to see if groups would reveal any statistically significant difference prior to instruction and to ensure that any possible comparative effects attributed to instruction would not be related to prior knowledge of any of the groups (see Appendix II).

\subsubsection{Post-tests}

For reminder purposes, the study set out to investigate both immediateand delayed effects of instruction; in this way, two post-tests were conducted at two different points in time right after instruction was secured: one post-test administered immediately after instruction and another delayed two months after the instructional treatment.

\subsubsection{The Immediate Post-test}

Regarding the immediate post-test, it was administered to the FonF group a week after instruction took place to investigate whether instruction in general, and FonF in particular, had different learning effects (see hypothesis 1). It was similar to the pre-test but not identical. It also contained an untimed GJT with 16 sentences, split evenly between grammatical and ungrammatical and running across the same levels of construction, but the test items were different. The subjects were given the same test direction as in the pre-test (see Appendix III).

\subsubsection{The Delayed Post-test}


As regards the delayed post-test, it was administered to the subjects two months after the treatment so as to find out if the gains were maintained i.e. whether FonF instruction had long-term effects. The test-takers completed the test in the same conditions as they completed the two previous tests: the delayed post-test was similar in content to the pre-test and the immediate posttest, but in no way identical (see Appendix IV).

\subsection{Scoring the GJT}

It may be informative to note that the same scoring procedure was adopted in the pre-, post-, and delayed post-tests. Each test item was dichotomously responded to as grammatical or ungrammatical, and scored on a 0 to 1 point scale. The participants were awarded a score of 1 if they judged a sentence correctly, giving a maximum possible score of 16 . Incorrect judgments were all scored 0 - all tests were worth at most sixteen points. There were no failures, whatsoever, on the part of the respondents to respond to a test item.

\subsection{Analysis}

A two-level between-subjects variable was adopted to define instruction (namely, FonF instruction and No instruction), and a three-level within-subjects variable (T0, T1, and $\mathrm{T} 2$ ) to operationalize temporal progress which included the pre-test and the two post-tests. Raw scores were entered and calculated for further use in the statistical analyses using the Statistical Package for the Social Sciences (SPSS) software (version 17.0). In order to answer the two research questions, and thus put our hypotheses to the test, we submitted the raw scores for the untimedGJT to an Independent-Samples TTest (a between-subjects design for testing hypothesis 1) and a Paired-Samples T-Test (a within-subjects design for testing hypothesis 2).

Why use the Independent-Samples T-Test? This is used to compare groups of participants that are not related and that are independent from one another. Why use the Paired-Samples T-Test? This test is sometimes called a repeated measures design where participants in the first group are the same as participants in the second group. It was used in the present study because our second research question called for the repeated measurement of the responses from the same individual. Data were collected on more than one occasion, that is, where subjects were followed over a period of time and asked similar questions at different times (i.e., comparing 'before and after' values).

\subsection{Results and Discussion}

Third year LMD university English language learners $(N=51)$ took the untimedGJT. The Independent-Samples T-Test- a between-subjects design conducted on the pre-test scores of both groups revealed no statistically significant difference prior to instruction between $\mathbf{F o n F}$ subjects $(\mathrm{M}=8.22, \mathrm{SD}$ $=1.423)$ and the control group $(\mathrm{M}=8.38, \mathrm{SD}=1.345), t(49)=-.393, p \leq .05$ (see Tables $1 \mathrm{a} \& b)$. Since the $p$-value denoted by "Sig. (2-tailed)" is .696, i.e. 
greater than 0.05 , it can be concluded that there is no significant difference between the means. Therefore, these results indicate that any comparative, or say differential, effects attributed to instruction will not be related to prior knowledge of any of the groups.

\section{Hypothesis 1.}

In pursuit of our aims, and in order for us to answer our first research question and therefore test the first hypothesis, an Independent-Samples $\boldsymbol{T}$ Test was conducted on the immediate post-test scores showing a statistically significant difference due to instruction between the FonF training condition $(\mathrm{M}=14.56, \mathrm{SD}=1.340)$ and the comparison group $(\mathrm{M}=8.78, \mathrm{SD}=1.444)$, $t(49)=14.785, p \leq .05$ (see Tables $2 \mathrm{a} \& \mathrm{~b}$ ). What does this mean? Since the $p$ value is .000 , i.e. less than 0.05 (or 5 percent), this suggests that there is a significant difference between the means. Therefore, we reject the null hypothesis that instruction does not make a difference or that there is no difference in the short term learning of parallel grammar structures between the two groups. Put another way, this indicates that the null is incorrect, that there is a relationship between FonF instruction and the learning of parallel grammar structures, and that the difference is not likely to be a result of chance.

\section{Hypothesis 2.}

In order for us to answer the second research question and as such test the second hypothesis, a Paired-Samples T-Test- a within-subjects design was conducted on the post-test scores of the FonF group, comparing the immediate post-test scores $(\mathrm{M}=14.56, \mathrm{SD}=1.340)$ and those of the delayed post-test $(\mathrm{M}=14.00, \mathrm{SD}=1.271), t(26)=5.701, p \leq .05$ (see Tables 3a,b\&c). Again, since the $p$-value is .000 , i.e. less than 0.05 (or 5 percent), we can conclude, as hypothesized, that there are statistically significant gains in the delayed post-test comparable to those of the immediate post-test (i.e. a slight regression in mean scores from $14.56 \pm 1.34$ points to $14.00 \pm 1.27$ points, but a statistically significant improvement in comparison with mean scores of the FonF group displayed in Table 1a b); therefore, we can reject the null hypothesis that the gains of instruction will not be maintained in the long-term for the FonF group. Stated otherwise, given that the effect was lasting for the experimental group who did not lose ground, this is indicative that the null does not stand, that there is a relationship between FonF instruction and longterm effect on learning of target structures, and that the result is not likely to be due to chance (i.e. there is $0 \%$ chance of observing a mean difference of .556 between the paired samples' performances (see Table $3 \mathrm{c}$ below). Table (3b) below presents the data on the extent to which the two variables are similar or correlated. As we have expected, there is a high correlation between the two variables.

\section{Conclusion and Recommendations}


We are drawing to the close of this paper and so far have discussed the role of FonF instruction in the development of L2 grammatical structures, namely parallel structures. The results of the present study are very telling. Be that as it may, we believe that the pedagogical provision of grammar instruction with no practice on the part of the learners is likely to result in nontarget-like accuracy. Therefore, tasks promoting language practice are very much in order for input to translate into intake, and for stabilized interlanguage to break free and keep away from being fossilized.

Of note also is that the value of FonF instruction may vary depending on complexity of the grammar structure under study. At any rate, it can be claimed that the present study tested a variety of parallel constructions ranging from single words up to clauses, though it did not set out to measure the difference therein specifically. Research studies targeting both simple and complex L2 forms are, therefore, very much warranted.

Of note also, for a coherent picture of FonF to emerge, more research studies trying out other tests that are production-based are in order.

\section{The T-Tests Tables}

\begin{tabular}{|ll|c|c|c|c|}
\hline Test & Groups & $\mathrm{N}$ & Mean & Std. Deviation & $\begin{array}{c}\text { Std. } \\
\text { ErrorMean }\end{array}$ \\
\hline Pre-Test & FonFG & 27 & 8.22 & 1.423 & .274 \\
& ControlG & 24 & 8.38 & 1.345 & .275 \\
\hline
\end{tabular}

Table 1a. Group Statistics

\begin{tabular}{|c|c|c|}
\hline & $\begin{array}{c}\text { Levene' } \\
\text { s Test } \\
\text { for } \\
\text { Equality } \\
\text { of } \\
\text { Varianc } \\
\text { es }\end{array}$ \\
\hline & \multicolumn{3}{|l|}{} \\
& t-test for Equality of Means & \multicolumn{2}{|l|}{$95 \%$} \\
& & $\begin{array}{c}\text { Confidence } \\
\text { Interval of } \\
\text { the } \\
\text { Difference }\end{array}$ \\
\hline
\end{tabular}




\begin{tabular}{|c|c|c|c|c|c|c|c|c|c|}
\hline & $\mathrm{F}$ & Sig & $\mathrm{t}$ & Df & $\begin{array}{l}\text { Sig. } \\
(2- \\
\text { taile } \\
\text { d) }\end{array}$ & $\begin{array}{c}\text { MeanDiffere } \\
\text { nce }\end{array}$ & $\begin{array}{c}\text { Std. } \\
\text { ErrorDiffere } \\
\text { nce }\end{array}$ & $\begin{array}{c}\text { Low } \\
\text { er }\end{array}$ & $\begin{array}{l}\text { Upp } \\
\text { er }\end{array}$ \\
\hline $\begin{array}{ll}\text { Pre } & \text { Equal } \\
- & \text { varianc } \\
\text { Tes es } \\
\text { t } & \text { assume } \\
& \text { d }\end{array}$ & $\begin{array}{c}.11 \\
4\end{array}$ & $\begin{array}{l}73 \\
7\end{array}$ & $\begin{array}{c}- \\
.39 \\
3\end{array}$ & 49 & .696 & -.153 & .389 & -.935 & .629 \\
\hline $\begin{array}{l}\text { Equal } \\
\text { varianc } \\
\text { es not } \\
\text { assume } \\
\text { d }\end{array}$ & & & $\begin{array}{c}- \\
.39 \\
4\end{array}$ & $\begin{array}{c}48.80 \\
1\end{array}$ & .695 & -.153 & .388 & -.932 & .627 \\
\hline
\end{tabular}

Table 1b. Independent-Samples T-Test for Pre-test Scores of both Groups

\begin{tabular}{|ll|c|c|c|c|}
\hline & & & Mea \\
Test & Groups & $\mathrm{N}$ & $\mathrm{n}$ & $\begin{array}{c}\text { Std. } \\
\text { Deviatio } \\
\mathrm{n}\end{array}$ & $\begin{array}{c}\text { Std. } \\
\text { ErrorMea } \\
\mathrm{n}\end{array}$ \\
\hline $\begin{array}{ll}\text { ImmediatePost } \\
\text {-Test }\end{array}$ & FonFG & 2 & 14.5 & 1.340 & .258 \\
& & 7 & 6 & & \\
& Control & 2 & 8.79 & 1.444 & .295 \\
\hline
\end{tabular}

Table 2a. Group Statistics

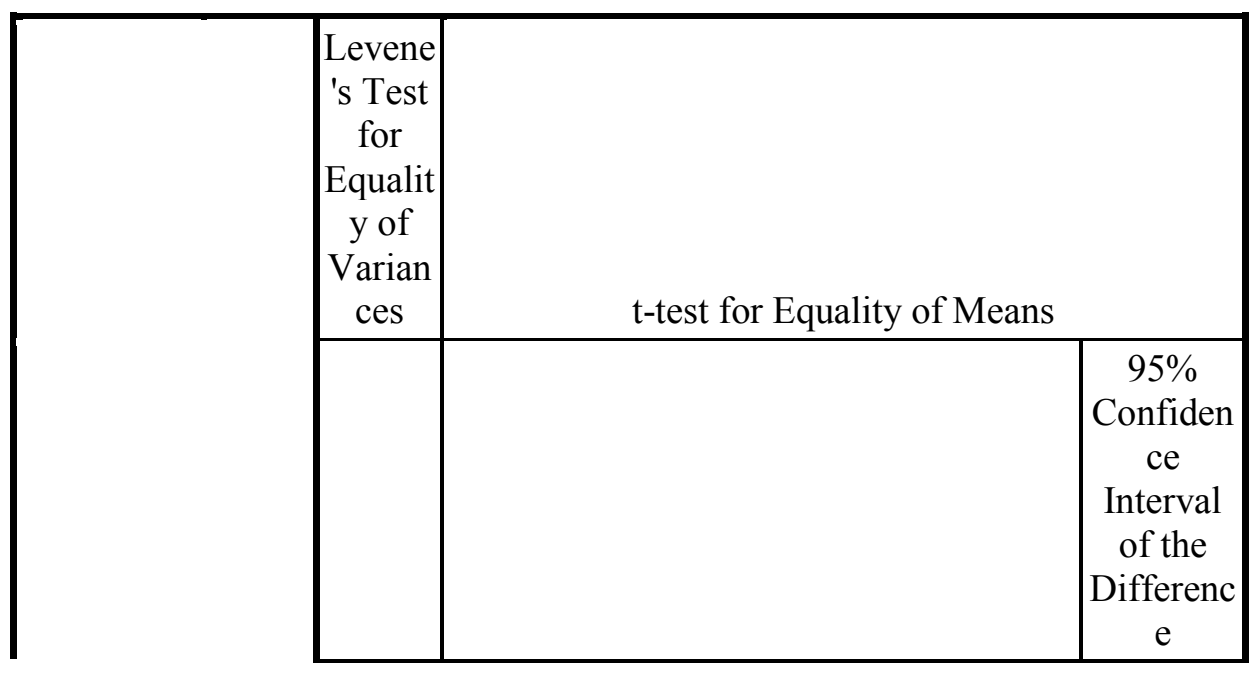


Preemptive and Reactive Focus-on-Form Instruction:

Effect on learning parallel grammatical structures

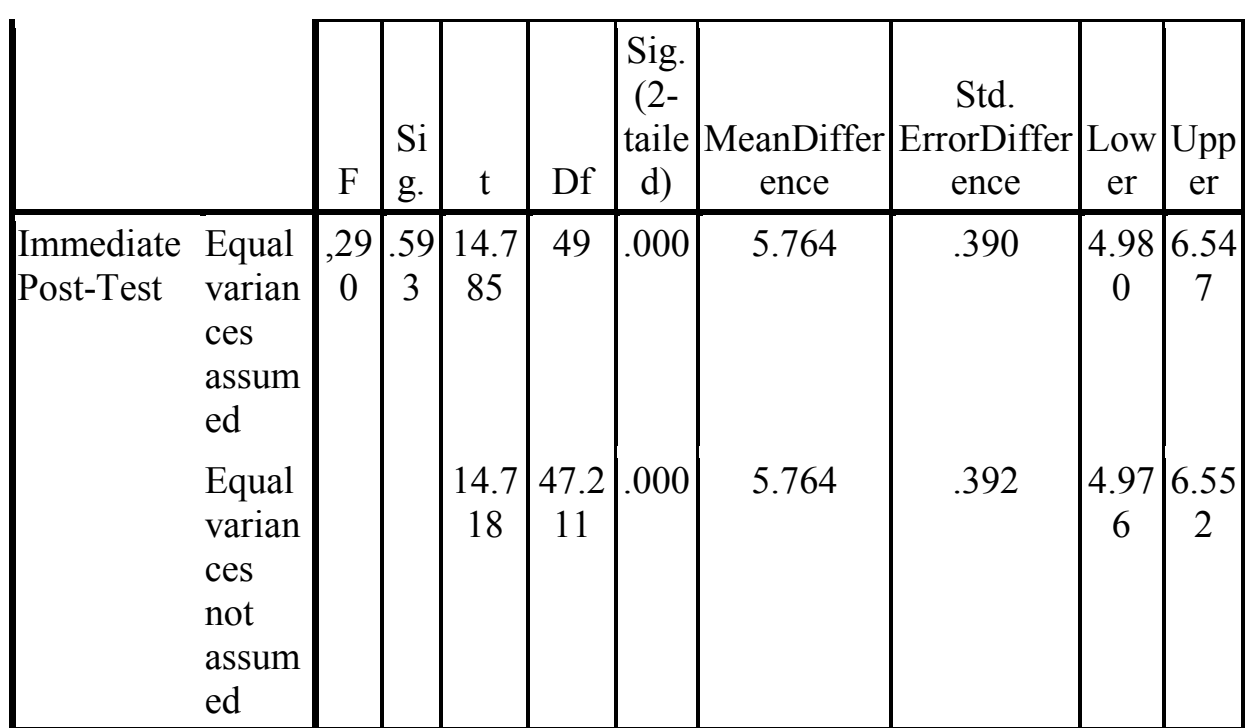

Table 2b. Independent-Samples T-Test for Immediate Post-test Scores of both Groups

\begin{tabular}{|rr|c|c|c|c|}
\hline & & Mean & $\mathrm{N}$ & Std. Deviation & $\begin{array}{c}\text { Std. } \\
\text { ErrorMean }\end{array}$ \\
\hline Pair 1 & $\begin{array}{r}\text { FonFImmediatePost- } \\
\text { Test }\end{array}$ & 14.56 & 27 & 1.340 & .258 \\
& $\begin{array}{r}\text { FonFDelayedPost- } \\
\text { Test }\end{array}$ & 14.00 & 27 & 1.271 & .245 \\
\hline
\end{tabular}

Table 3a. PairedSamplesStatistics

\begin{tabular}{|ll|c|c|c|}
\hline & $\mathrm{N}$ & Correlation & Sig. \\
\hline Pair 1 & $\begin{array}{l}\text { FonF Immediate Post-Test } \\
\text { \&FonF Delayed Post-Test }\end{array}$ & 27 & .926 & .000 \\
\hline
\end{tabular}

Table 3b. PairedSamplesCorrelations 


\begin{tabular}{|c|c|c|c|c|c|c|c|c|}
\hline & \multicolumn{5}{|c|}{ PairedDifferences } & \multirow[b]{3}{*}{$\mathrm{t}$} & \multirow[b]{3}{*}{$\mathrm{df}$} & \multirow{3}{*}{$\begin{array}{l}\text { Sig. (2- } \\
\text { tailed) }\end{array}$} \\
\hline & \multirow[b]{2}{*}{ Mean } & \multirow{2}{*}{$\begin{array}{c}\text { Std. } \\
\text { Deviation }\end{array}$} & \multirow{2}{*}{$\begin{array}{c}\text { Std. } \\
\text { ErrorMean }\end{array}$} & \multicolumn{2}{|c|}{$\begin{array}{c}95 \% \\
\text { Confidence } \\
\text { Interval of } \\
\text { the } \\
\text { Difference }\end{array}$} & & & \\
\hline & & & & Lower & Upper & & & \\
\hline $\begin{array}{ll}\text { Pair } & \text { FonF } \\
1 & \text { Immediate } \\
& \text { Post-Test - } \\
& \text { FonF } \\
& \text { Delayed } \\
& \text { Post-Test }\end{array}$ & .556 & .506 & .097 & .355 & .756 & 5.701 & 26 & .000 \\
\hline
\end{tabular}

Table 3c. Paired-Samples T-Test for Immediate \& Delayed Post-test Scores of FonF Group

\section{Bibliography}

[1] Williams, J. Learner-generated attention to form. Language Learning:49/4. 1999, 583-625.

[2] Long, M. Focus on form: A design feature in language teaching methodology. In K. deBot, C. Kramsch, \& R. Ginsberg, (eds.), Foreign language research in cross-cultural perspective. Amsterdam: John Benjamin. 1991, 39-52.

[3]Long, M., \& Robinson, P. Focus on form: Theory, research and practice. In C. Doughty \& J. Williams (eds.), Focus on form in classroom second language acquisition. Cambridge: CUP. 1998, 15-41.

[4]Krashen, S.Principles and practice in second language acquisition. Oxford: Pergamon Press. 1982.

[5]White, L. Against comprehensible input: The Input Hypothesis and the development of second-language competence. Applied Linguistics:8/2. 1987, 95-110.

[6]Larsen-Freeman, D. On the teaching and learning of grammar: Challenging the myths. In F. Eckman, D. Highland, L. P. J. Mileham, \& R. Weber (eds.), Second language acquisition theory and pedagogy. Mahwah, NJ: Lawrence Erlbaum. 1995, 131-50.

[7]Cadierno, T. Formal instruction from a processing perspective: An investigation into the Spanish past tense. Modern Language Journal: 79. 1995, 179-93.

[8]Bardovi-Harlig, K.Tense and aspect in second language acquisition: Form, meaning, and use. Oxford: Blackwell. 2000. 
[9]Ellis, N. C. At the interface: Dynamic interactions of explicit and implicit language knowledge. Studies in Second Language Acquisition:27. 2005, 305-352.

[10]Long, M. Does second language instruction make a difference? A review of the research. TESOL Quarterly:17/3. 1983, 359-382.

[11]Ellis, R. Investigating form-focused instruction. Language Learning:51, supplement 1.2001, 1-46.

[12]Ellis, R. Does form-focused instruction affect the acquisition of implicit knowledge? A review of the research. Studies in Second Language Acquisition:24. 2002, 223-236.

[13]Harley, B. Functional grammar in French immersion: A classroom experiment. Applied Linguistics:10/3. 1989, 331-359.

[14] White, L. Adverb placement in second language acquisition: some effects of positive and negative evidence in the classroom. Second Language Research:7/2. 1991, 133-161.

[15]Sharwood Smith, M. A. Input enhancement in instructed SLA. Studies in Second Language Acquisition:15/2. 1993, 165-179.

[16]Schmidt, R. Awareness and second language acquisition. Annual Review of Applied Linguistics: 13/1. 1993, 206-226.

[17]Long, M. Instructed interlanguage development. In L. M. Beebe (ed.), Issues in second language acquisition: Multiple perspectives. Cambridge, MA: Newbury House/Harper and Row.1988, 115-141

[18]Spada, N. Form-focused instruction and second language acquisition: a review of classroom and laboratory research. Language Teaching: 30. 1997, 73-87.

[19]Ellis, R., Basturkmen, H., \&Loewen, S. Learner uptake in communicative ESL lessons. Language Learning: 51/2. 2001a, 281-318.

[20] Long, M. The role of linguistic environment in second language acquisition. In W. C. Ritchie \& T.K. Bhatia (eds.), Handbook of second language acquisition. New York: Academic Press.1996, 413-468

[21] Swain, M. Communicative competence: some roles of comprehensible input and comprehensible output in its development'. In S. M. Gass and C. G. Madden (eds.), Input in Second Language Acquisition. Heinle and Heinle Publishers. 1985: 235-353.

[22]Lightbown, P. M., \&Spada, N. Focus-on-Form and corrective feedback in communicative language teaching. Studies in Second Language Acquisition: 12/4. 1990, 429-448.

[23]Doughty, C. \& Williams, J. Pedagogical choices in focus on form. In C. Doughty \& J. Williams (eds.). Focus on form in classroom second language acquisition. Cambridge: CUP.1998.

[24]Leow, R. P. Attention, awareness, and foreign language behavior. Language Learning: 51, supplement 1. 2001, 113-155. 
[25]Fotos, S. Integrating grammar instruction and communicative language use through grammar consciousness-raising tasks. TESOL Quarterly:28/2. 1994, 323-351.

[26]Loewen, S. Variation in the frequency and characteristics of incidental focus on form. Language Teaching Research: 7/3. 2003, 315-345.

[27] Williams, J. The effectiveness of spontaneous attention to form. System: 29/3. 2001, 325-340.

[28] Ellis, R., Basturkmen, \& H., Loewen, S. Doing Focus-on-Form. System: 30/4. 2002, 419-432.

[29]DeKeyser, R. Beyond focus on form: Cognitive perspectives on learning and practicing in L2 grammar. In C. Doughty \& J. Williams (eds.). Focus on form in classroom second language acquisition. Cambridge: CUP.1998.

[30] Harley, B. The role of focus-on-form tasks in promoting child L2 acquisition. In C. Doughty \& J. Williams (eds.). Focus on Form in Classroom Second Language Acquisition. Cambridge, England: Cambridge University Press. 1998, 156-174.

[31]Lightbown, P. M. The importance of timing in focus on form. In C. Doughty \& J. Williams (eds.). Focus on form in classroom second language acquisition. Cambridge: CUP.1998.

[32]Spada, N. \&Lightbown, P. M. Instruction and the development of questions in L2 classrooms. Studies in Second Language Acquisition: 15/2. 1993, 205-24.

[33] Doughty, C. Second language instruction does make a difference:

Evidence from an empirical study of ESL relativization. Studies in Second

Language Acquisition: 13/4. 1991, 431-469.

[34]Leeman, J., Arteagoitia, I., Fridman, B., \& Doughty, C. Integrating attention to form with meaning: Focus on form in content-based Spanish instruction. In R. Schmidt (ed.), Attention and awareness in foreign language learning. Honolulu: University of Hawai'i Press. 1995, 217-258

[35] Doughty, C. \& Varela,E. Communicative focus on form. In: C. Doughty \& J. Williams (eds.). Focus on form in classroom $m$ second language acquisition. Cambridge: CUP. 1998.

[36]Day, E. M. \&Shapson,S. M. Integrating formal and functional approaches to language teaching in French immersion: An experimental study. Language Learning:41/1. 1991, 25-58.

[37]Bialystok, E. Psycholinguistic dimensions of second language proficiency. In W. Rutherford \& M. A. Sharwood Smith (eds.). Grammar and second language teaching: A book of readings. New York: Newbury House. 1989, 31-50.

[38]Bialystok, E. Explicit and implicit judgments of L2 grammaticality. Language Learning: 29. 1979, 81-103. 
Appendices

\section{Appendix I. Pilot test}

Which of the following sentences is grammatically parallel and which is nonparallel? Tick as appropriate.

Single words:

1. The ceremony was both long and tedious.[Grammatical....... / Ungrammatical.......]

2. It is a time not for words, but for action. [Grammatical....... / Ungrammatical.......]

3. You must either grant his request or incur his ill will.[Grammatical....... / Ungrammatical.......]

4. Susan is smart, diligent, and a hard worker. [Grammatical....... / Ungrammatical.......]

5. Ellen likes hiking, the rodeo, and to take afternoon naps. [Grammatical....... / Ungrammatical.......]

6. The obvious choices were to become a soldier or he could join the priesthood. [Grammatical....... / Ungrammatical.......]

7. My favourite subjects are: history, psychology, and math. [Grammatical....... / Ungrammatical.......]

8. To succeed inthisjob,youmustbothlearn fast andwork hard.[Grammatical....... / Ungrammatical.......]

\section{Phrases:}

9. Buying a car and beginning her job were the next steps in her life. [Grammatical....... / Ungrammatical.......]

10. In spring, in summer, or winter, theyusuallyspendtheirweekends sleeping.[Grammatical....... / Ungrammatical.......]

11. His satisfaction lies not in his title but his daily work.[Grammatical....... / Ungrammatical.......]

12. I would rather pay for my education than receive financial aid. [Grammatical....... / Ungrammatical.......]

13. Theycan't decidewhethertotakeacruise or togoon asafari.[Grammatical....... / Ungrammatical.......]

\section{Clauses:}

14. Thecandidatebelievesthatthiscountryisreadyforchange, that the peoplearewillingtosacrifice, andthattherecanbenochangewithoutsacr ifice.[Grammatical....... / Ungrammatical.......]

15. Hisideaofarelaxingevening iseitherbiking aroundtheislandorthat he watchesthesunsetoverthelake.[Grammatical.......

Ungrammatical.......] 
16. The insurance clerk knew that we had paid our bill and we had our receipt. [Grammatical....... / Ungrammatical.......]

\section{Appendix II. Pre-test}

Which of the following sentences is grammatically parallel and which is nonparallel? Tick as appropriate.

\section{Single words:}

1. Galileo studied, thought, and experimented. [Grammatical....... / Ungrammatical.......]

2. They waited four hours at the airport, reading and sleeping. [Grammatical....... / Ungrammatical.......]

3. The doctor recommended plenty of food, sleep and exercising. [Grammatical....... / Ungrammatical.......]

4. I am happierat mynew jobthanIwasatmyoldone.[Grammatical....... / Ungrammatical.......]

5. Forthefirsttimeinhislifehehadajob,ahome, andfamily.[Grammatical... .... / Ungrammatical.......]

6. Syntax, morphology, and the area of phonology are the core areas of linguistics. [Grammatical....... / Ungrammatical.......]

7. I was happy and my parents happy too. [Grammatical....... / Ungrammatical.......]

8. Global warming affects humans, the environment, and is scary. [Grammatical. / Ungrammatical.......]

Phrases:

9. Come to the meeting prepared to take notes and to ask questions.

[Grammatical....... / Ungrammatical.......]

10. To chew carefully and eating slowly are necessary for good digestion.

[Grammatical....... / Ungrammatical.......]

11. To swim in a lake is more pleasant than swimming at the seashore. [Grammatical....... / Ungrammatical.......]

12. Thecatclimbedoverthe fence, upthe tree, andontothe roofofthehouse.[Grammatical....... / Ungrammatical.......]

13. Thejudgetold hertotake the stand andtell thetruth.[Grammatical....... Ungrammatical........]

\section{Clauses:}

14. A father who spends time with his son and who thoughtfully answers his son's questions will be respected and loved. [Grammatical....... / Ungrammatical.......] 
15. He appreciatedneither what she said nor how she said it.[Grammatical....... / Ungrammatical.......]

16. She'sasking notwherehewentbutthe timehewent. [Grammatical....... / Ungrammatical.......]

\section{Appendix III. Immediate Post-Test}

Which of the following sentences is grammatically parallel and which is nonparallel? Tick as appropriate.

Single words:

1. The young actor was tall, dark, and had a handsome face.

[Grammatical....... / Ungrammatical.......]

2. He introduced aids to understanding such as paintings, recordings, pieces of sculpture, and guest lecturers. [Grammatical....... /

Ungrammatical.......]

3. He was not only kind but also knew when to help people.

[Grammatical....... / Ungrammatical.......]

4. Bill not only passed the test but also wrote the best paper in the class.

[Grammatical....... / Ungrammatical.......]

5. He was a waiter, a tour guide, and taught at school.

[Grammatical....... / Ungrammatical.......]

6. It's harder to do long divisions than dividing with a calculator.

[Grammatical....... / Ungrammatical........]

7. The dentist did not let me eat or drink anything for at least an hour.

[Grammatical....... / Ungrammatical.......]

8. The ambassador spoke quietly and with force. [Grammatical......./ Ungrammatical.......]

\section{Phrases:}

9. To support his family and to put himself through college, he worked seven hours a day. [Grammatical....... / Ungrammatical.......]

10. I debated whether I should give the beggar money or to offer him food. [Grammatical....... / Ungrammatical.......]

11. I hope to vacation either in Spain or in Ireland.[Grammatical....... / Ungrammatical.......]

12. The instructor recommended several books for outside reading and that we should attend a play dealing with our subject. [Grammatical....... / Ungrammatical........]

13. Goingtoamovieis moreexpensive than to rentavideo. [Grammatical....... / Ungrammatical.......]

\section{Clauses:}


14. If you write or if you telephone, wait for two weeks until I return from Singapore. [Grammatical......./ Ungrammatical.......]

15. Unfortunately for all of us, what she says and she doesare very often two different things! [Grammatical....... /

Ungrammatical........]

16. My employer informed me that I would be sent to Hong Kong and I should make arrangements to leave in about two weeks.

[Grammatical....... / Ungrammatical.......]

\section{Appendix IV. Delayed Post-Test}

Which of the following sentences is grammatically parallel and which is nonparallel? Tick as appropriate.

Single words:

1. Late for the dance, Jim dressed hastily and carelessly.

[Grammatical....... / Ungrammatical.......]

2. He made learning more enjoyable and more lasting.

[Grammatical....... / Ungrammatical.......]

3. The French, the Italians, Spanish, and Portuguese.

[Grammatical....... / Ungrammatical.......]

4. They have space for a computer but not a cupboard.

[Grammatical....... / Ungrammatical.......]

5. He told us that the novel was timely, informative, and could hold our interest. [Grammatical....... / Ungrammatical.......]

6. Bothmyplaneticketandmypassportwerelost.[Grammatical....... / Ungrammatical.......]

7. Nowisthetime toorganize,plan, and toact.[Grammatical....... / Ungrammatical.......]

8. Theirweddingdaywasbeautiful,bright, andjoyful.[Grammatical....... / Ungrammatical........]

\section{Phrases:}

9. Jack passes his time doing crossword puzzles and building model airplanes. [Grammatical....... / Ungrammatical.......]

10. Carlos wasted his first year at college by not studying enough and spending too much time at parties. [Grammatical....... Ungrammatical.......]

11. Dentists advise brushing the teeth after each meal and to avoid too much sugar in the diet. [Grammatical....... / Ungrammatical.......]

12. My dog likes not only to play fetch, but also to chase cars.[Grammatical....... / Ungrammatical.......]

13. Investinginhiscompanyisthesame as tothrowyour moneyaway.[Grammatical....... / Ungrammatical.......] 


\section{Clauses:}

14. I forgot that my research paper was due on Tuesday and my teacher had said he would not accept late papers. [Grammatical....... / Ungrammatical.......]

15. Areyoustayinghomebecause youaretiredorbecauseitisaschoolnight? [Grammatical....... / Ungrammatical.......]

16. Sheisa person who works hard and gets along well with others. [Grammatical....... / Ungrammatical.......] 